\title{
PERANCANGAN DAN IMPLEMENTASI VLC SEBAGAI MEDIA TRANSMISI VIDEO STREAMING
}

\author{
DESAIN AND IMPLEMENTATION VLC AS MEDIA TRANSMISSION OF VIDEO \\ STREAMING \\ Andi Imam Dwi Resky Mudassir', Tengku Ahmad Riza, S.T., M.T. ${ }^{2}$, Denny Darlis, S.Si,M.T. 3
${ }^{1,2,3}$ Prodi D3 Teknik Telekomunikasi, Fakultas IImu Terapan, Universitas Telkom
'andiimamdwirezky@gmail.com, ${ }^{2}$ tengkuriza@tass.telkomuniversity.ac.id,
${ }^{3}$ denny.darlis@tass.telkomuniversity.ac.id

\begin{abstract}
Abstrak
LED (Light Emiting Diode) saat ini sebagian besar pemanfaatannya hanya sebagai indikator ataupun sebagai penerang suatu ruangan. Pada perkembangan teknologi ini banyak menciptakan inovasiinovasi, yaitu $\angle E D$ saat sekarang ini dapat digunakan sebagai suatu media transmisi berkecepatan tinggi. Visible Light Communication (VLC) adalah sebuah system komunikasi yang memanfaatkan cahaya tampak sebagai media transmisi. Proyek akhir ini, dikembangkan suatu system VLC untuk mengirimkan suatu video streaming.video streaming di kirim melalui blok transmitter dengan memanfaatkan $\angle E D$ sebagai pengirim. Kemudian diterima oleh blok receiver dengan photodiode sebagai penerima informasi yang di kirimkan oleh $\angle E D$. Dalam pengiriman video streaming terbagi menjadi dua bagian, yaitu sinyal suara dan video streaming. Adapun hasil proyek akhir ini adalah dapat membuktikan video streaming dapat di kirim melalui system $V L C$ dengan jarak $45 \mathrm{~cm}$.
\end{abstract}

Kata kunci : visible light communication, light emiting diode, photodiode,video streaming.

\begin{abstract}
LED (Light Emiting Diode) is currently largely utilized only as an indicator or as a light of a room. In the development of this technology a lot to create innovations, the current LED can be used as a mediumspeed transmission medium. Visible Light Communication (VLC) is a communication system that utilizes visible light as a transmission medium. This final project, developed a VLC system to transmit a streaming video. Streaming video is sent through the transmitter block by utilizing the LED as the sender. It is then received by the receiver block with the photodiode as the receiver of the information transmitted by the LED. In streaming video delivery is divided into two parts, namely voice and video streaming. The final result of this project is to prove the video streaming can be sent through VLC system with a distance of $45 \mathrm{~cm}$.
\end{abstract}

Keywords: visible light communication, light emitting diode, photodiode, video streaming.

\section{PENDAHULUAN}

LED sekarang sebagian besar dijadikan sebagai penerang suatu ruangan. Namun Sebagaimana telah diketahui,bahwa cahaya lampu (tampak) bukan hanya di gunakan sebagai media penerangan tapi dapat juga digunakan sebagai media transmisi atau sebagai media pengirim suatu informasicahaya tampak (visible light) dapat mengefisienkan dalam pengiriman dan penerimaan suatu data. Dengan hanya menghidupkan lampu, maka komunikasi pun dapat dilakukan. Dengan adanya sistem Visible Light Commnucation ini dimungkinkan pemanfaatan lampu untuk mentransmisikan data. Teknologi $V L C$ ini dapat mengirim teks, suara, dan video seperti pada penelitian sebelumnya. Penelitian sebelumnya,system
$V L C$ digunakan untuk mengirim video. system tersebut bekerja dari sumber DVD player dengan memodulasi sinyal audio ke digital dan audio tetap analog dengan jarak antara pengirim dan penerima 1 meter.

Dengan adanya masalah diatas, maka dalam proyek akhir ini telah dibuat suatu system yang dapat mengirimkan video streaming dengan menggunakan system VLC dalam pentransmisiannya. Sehingga pemanfaatan lampu ruangan bukan hanya digunakan untuk penerangan saja, tetapi juga dapat di gunakan untuk mentransmisikan video streaming.

\section{DASAR TEORI}

2.1 Komunikasi Cahaya Tampak (Visible Light Communication) 
Komunikasi cahaya tampak (VLC) mengacu pada teknologi komunikasi yang memanfaatkan sumber cahaya tampak sebagai pemancar sinyal, udara sebagai media transmisi, dan fotodioda yang tepat sebagai komponen sinyal penerima.

\section{Pengirim VLC}

Pengirim pada sistem komunikasi cahaya tampak adalah sebuah pencahayaan LED.

\section{Penerima VLC}

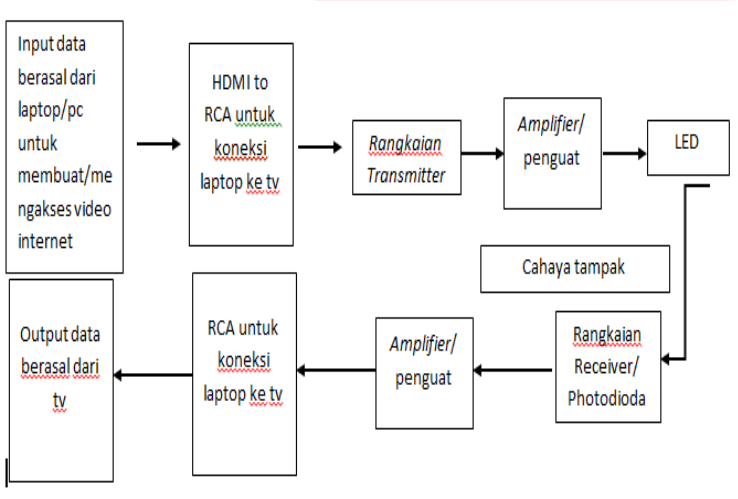

Gambar 2.1 Blok Diagram Sistem

Terdapat dua jenis penerima VLC yang bisa digunakan untuk menerima sinyal yang dikirim oleh pencahayaan LED

1. Fotodetektor - juga merujuk pada fotodioda atau penerima non-imaging,

2. Sensor gambar - disebut juga sensor kamera

\subsubsection{Sistem Komunikasi Cahaya Terpandu (Guided)}

Sistem Komunikasi cahaya terpandu (Guided optical communication) adalah sebuah sistem komunikasi cahaya yang menggunakan serat optik sebagai media transmisi.

\subsubsection{Sistem Komunikasi Cahaya Tak Terpandu (Unguided) \\ Sistem komunikasi cahaya tak} terpandu (unguided optical communication) atau yang sering disebut sistem komunikasi optik nirkabel (optical wireless communication) merupakan sistem komunikasi optik dengan menggunakan ruang bebas sebagai media transmisi cahaya.

\subsection{Video Streaming}

Video Streaming adalah komunikasi yang dilakukan melalui sistem broadcast akses internet untuk menghasilkan sebuah gambar, video streaming bukan hal yang baru bagi kita di tanah air (Indonesia), munculnya 3G (Generasi ke Tiga) pada sebuah telephone seluler video streaming bagaikan jamur bertumbuhan dimana-mana, hingga kepelosok tanah air.

\subsection{Video Analog}

Analog video tersusun dari gelombang bersambung yang bervariasi, dengan kata lain nilai sinyal akan memiliki angka yang beragam tetapi terbatas pada batas maksimum dan minimum yang diijinkan.

\subsection{Penguat (Amplifier)}

Rangkaian komponen elektronika yang dipakai untuk menguatkan daya (atau tenaga secara umum). Dalam bidang audio dan video, amplifier akan menguatkan signal suara dan video yaitu memperkuat signal arus (I) dan tegangan (V) listrik dari inputnya menjadi arus listrik dan tegangan yang lebih besar (daya lebih besar) di bagian outputnya.

\subsection{Cut Off}

Frekuensi cut-off adalah nilai frekuensi saat daya daya turun menjadi setengah dari daya inputnya atau turun $3 \mathrm{~dB}$, atau dalam voltase adalah turun $0,7 \mathrm{Volt}$.

\subsection{Reserve Bias}

Reverse bias adalah kondisi dimana lapisan negatif dioda diberi tegangan positif dan lapisan positifnya diberi tegangan negatif.

\subsection{Photodioda}

Photodiode adalah jenis dioda yang bekerja karena pengaruh cahaya yang mengenainya, sehingga dalam fungsinya dioda jenis ini bisa digunakan untuk mendeteksi cahaya.
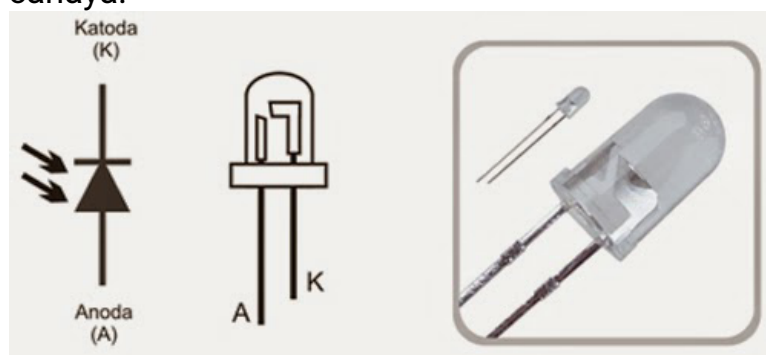

Gambar 2.2 Photodioda 


\section{$2.8 \angle E D$}

Light emitting diode ( $\angle E D)$ adalah suatu senikonduktor yang memancarkan cahaya.

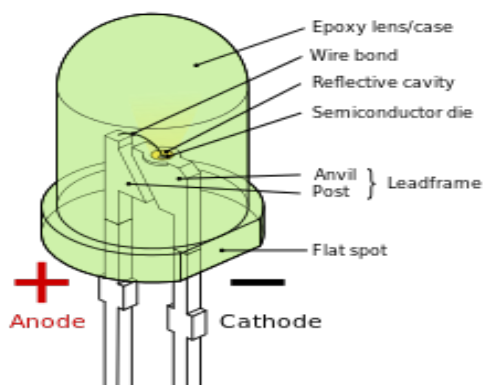

Gambar 2.3 $\angle E D$

\subsection{Filter $\angle P F$}

Digunakan untuk meredam sinyal dengan frekuensi besar (diatas frekuensi cut off) dan meloloskan sinyal dengan frekuensi kecil (dibawah frekuensi cut off).

\section{PERANCANGAN ALAT}

\subsection{Diagram Alir Pembuatan Sistem}

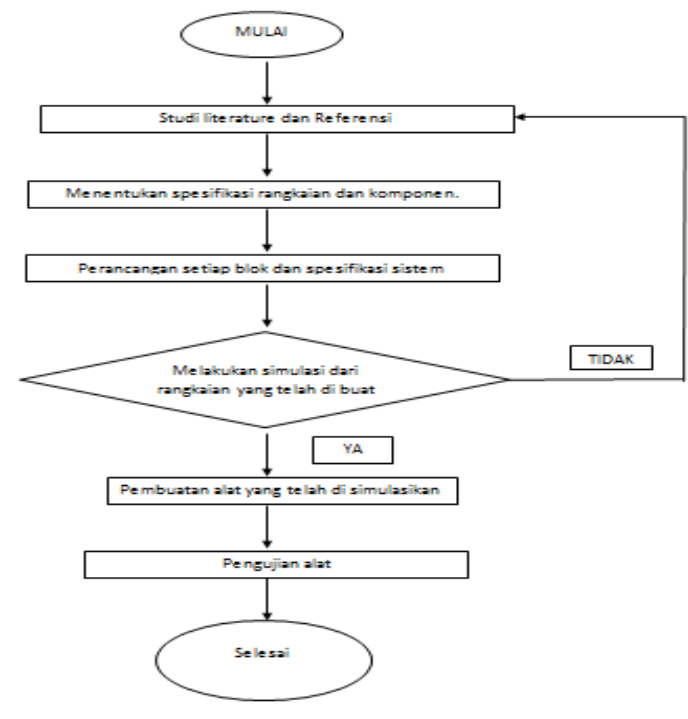

Gambar 3.1 Diagram Alir Pembuatan Sistem

Sistem yang dibuat terbagi menjadi 2 blok yaitu blok transmitter dan blok receiver. Gambar blok diagram keseluruhan dapat dilihat pada gambar dibawah ini :

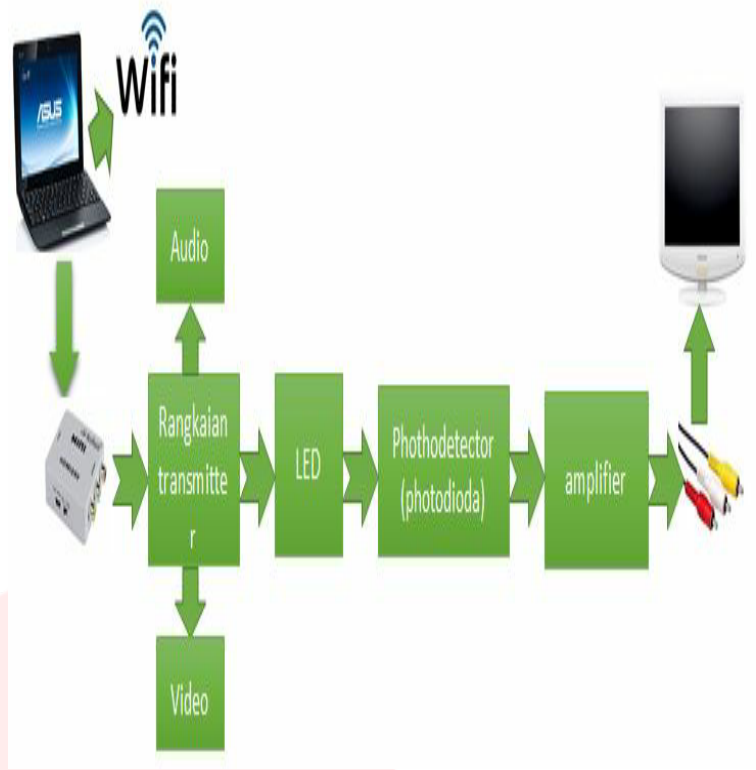

Gambar 3.2 Sistem kerja keseluruhan

\subsubsection{Blok Diagram Sistem}

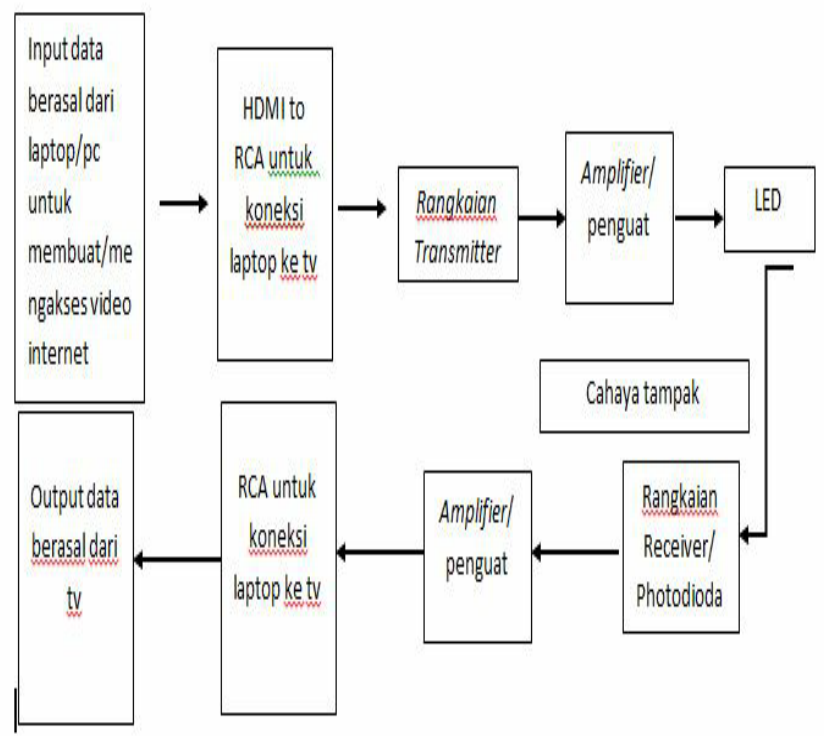

Gambar 3.3 Blok Diagram Sistem

\subsection{CARA KERJA SISTEM}

Output dari laptop/pc yang dihubungkan ke HDMI to RCA untuk membuat/mengakses video. Kabel HDMI to RCA ini membawa sinyal video untuk ditransmisikan dan dikuatkan oleh amplifier dan masuk ke rangkaian pengirim. Sinyal video akan dikirimkan malalui cahaya yang dihasilkan oleh $\angle E D$.

Setelah dikirimkan sinyal cahaya tersebut akan diterima oleh rangkaian photodiode, sinyal video diterima oleh 
photodiode driver kemudian diolah oleh rangkaian penerima, kemudian dikeluarkan di tv berupa video dari video internet tersebut.

\subsection{Blok TransmitterVideo}

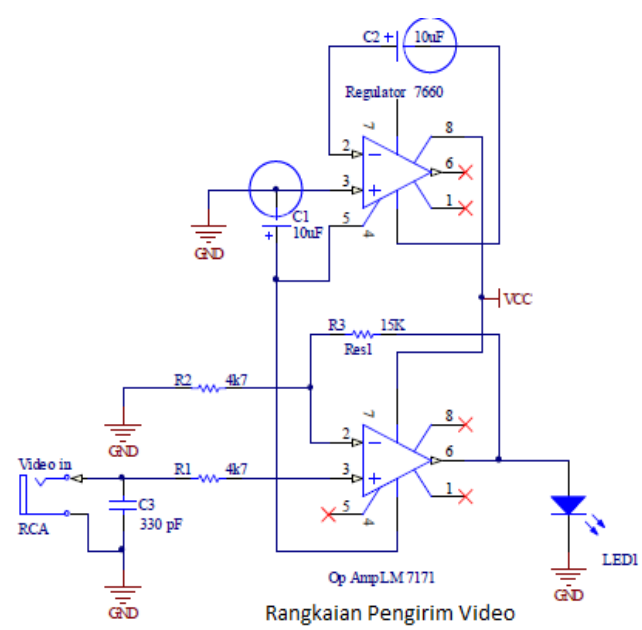

Gambar 3.4 Blok Transmitter Video

\subsection{Blok Transmitter Audio}

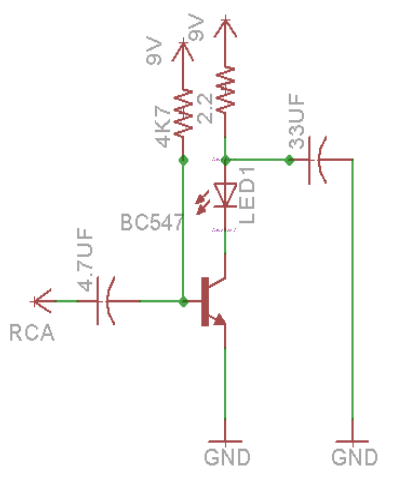

Rangaian Pengirim Audio

Gambar 3.5 Blok Transmitter Audio

\subsection{Blok Receiver Video}

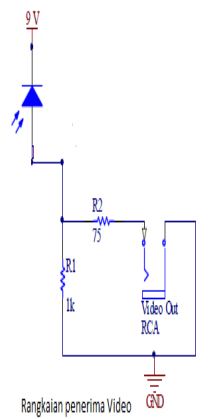

Gambar 3.6 Blok Receiver Video

\subsection{Blok ReceiverAudio}

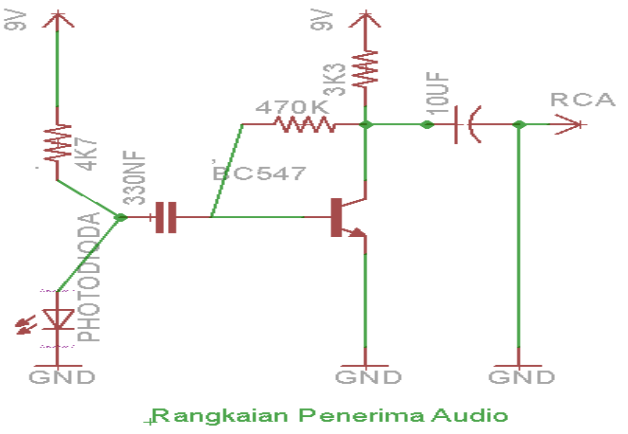

Gambar 3.7 Blok Receiver Audio

\subsection{Realisasi Perancangan}

Pada perancangan sistem ini terdapat 2 buah hardware yaitu transmitter $(T X)$, dan receiver $(R x)$.
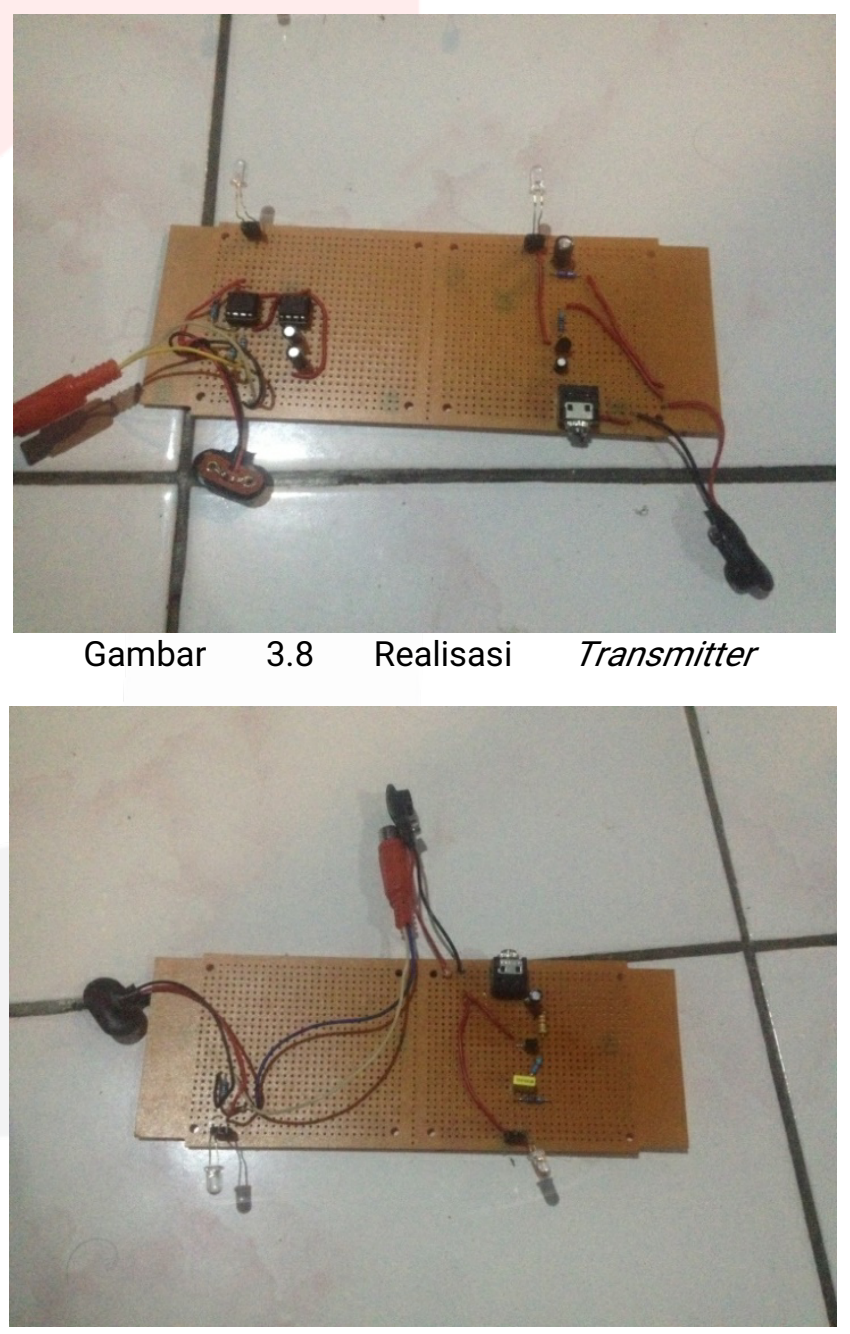

keseluruhan

Gambar

3.9

Realisasi

receiver keseluruhan

4. PENGUJIAN DAN ANALISIS

4.1 Tujuan Pengujian dan Pengukuran 
1. Pengujian Sistem Video Streaming

- Ping dan Kecepatan Wifi

- Menghitung Data Rate

2. Pengujian Transmitter

3. Pengujian Receiver

4. Pengujian Transmitterke Receivermengirim sinyal dari osiloskop

5. Pengujian Transmitter ke Receiver mengirim sinyal video dari laptop/pc

6. Pengujian Jarak

7. Pengukuran intensitas cahaya led

\section{Pengujian Sistem Video Streaming}

- Ping dan Kecepatan Wifi

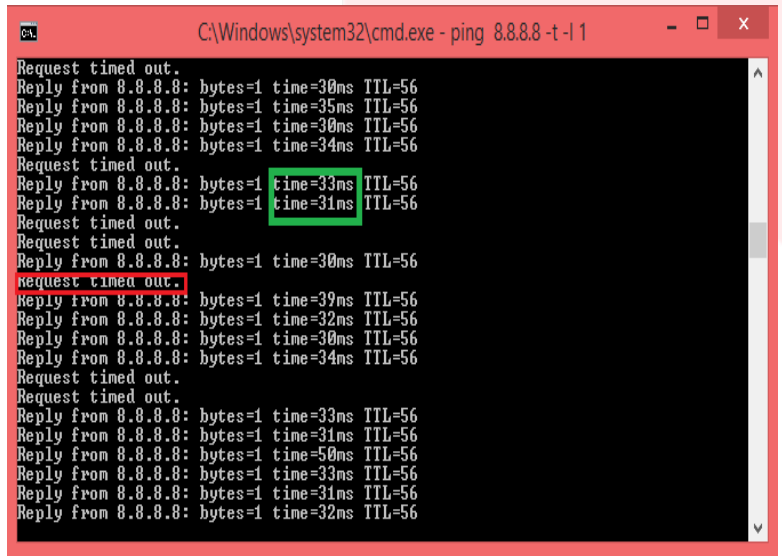

Gambar 4.1 Ping dan Kecepatan Wifi menggunakan kabel LAN

- Data Rate

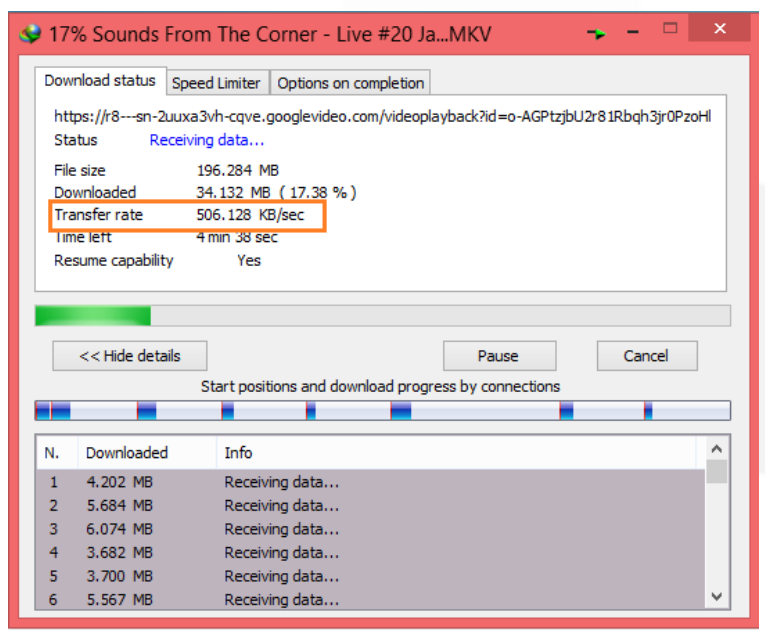

Gambar 4.2 Hasil Data Rate tanpa menggunakan kabel LAN

\section{Pengujian Menggunakan $\angle E D$}

Hasil keluaran pada monitor dengan menggunakan $\angle E D$ sebagai pengirim informasi dan photodiode sebagai penerimanya,dengan jarak tertentu.

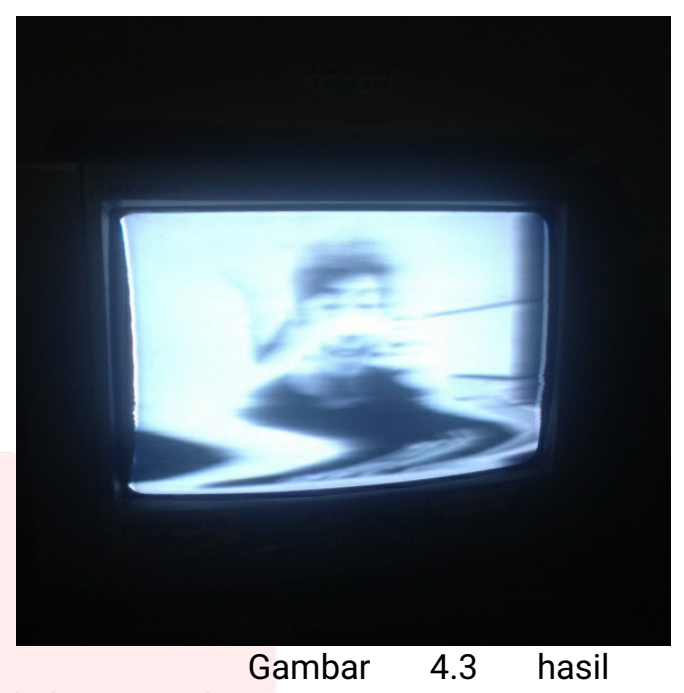

keluaran pada monitor

Hasil secara keseluruhan keluaran pada monitor dengan menggunakan $\angle E D$ sebagai pengirim informasi dan photodiode sebagai penerimanya.

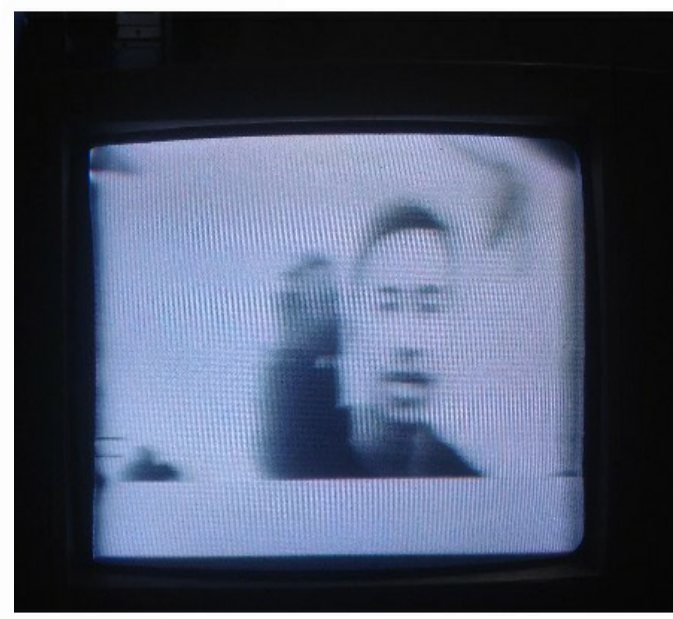

Gambar 4.4 hasil keluaran pada monitor

\section{Kesimpulan}

1. Pengiriman video dari Client ke Display dengan menggunakan sistem visible light communication dapat dilakukan dan dijalankan.

2. Video dapat dikirim dengan menggunakan sistem Visible Light Communication pada jarak maksimal $45 \mathrm{~cm}$.

3. Kualitas suara dan video akan semakin menurun apabila jarak lebih dari $45 \mathrm{~cm}$ dan sudut lebih dari $25^{\circ}$. Hal tersebut terjadi 
karena penurunan tegangan yang disebabkan karena sinyal yang dikirim tidak dapat diterima dengan sempurna.

4. Kondisi lingkungan gelap dan terang mempengaruhi jarak pengiriman video dari Transmiterke Receiver. Semakin gelap kondisi lingkungan, maka jarak tempuh

informasi yang dikirim dari Transmiter ke Receiversemakin jauh.

5. Sudut yang terbentuk dari Transmiter ke Receiver mempengaruhi jarak pengiriman video.

6. kecepatan wifi akan menurun tanpa menggunakan kabel LAN,dan kecepatan WIFI meningkat dengan menggunakan kabel LAN.

7. data rate berkurang tanpa menggunakan kabel LAN,dan data rate bertambah dengan menggunakan kabel LAN.

\section{DAFTAR PUSTAKA}

[1] Yulian, D., Darlis, D., \& Aulia, S. (2015). Perancangan dan Implementasi Perangkat Visible Light Communication Sebagai Transceiver Video. Jurnal Elektronika Telekomunikasi Terapan (JETT).2 (2): 196-206.

[2] Asfan Sabri, (2015). Pengertian dan kegunaan Video Streaming, http://www.kompasiana.com/aspan/p engertian-dan-kegunaan-video- streaming-

teleconfrence_55004944a3331159735 10373

[3] D Darlis., AR Darlis., \& MH Abibi (2016). Implementasi Sistem Penyiaran Musik Digital di Kafe menggunakan Visible Light Communication. Jurnal Elkomika,2016.5 (1).

[4] RH Ashary., D Darlis., \& S Aulia. (2016). Perancangan dan Implementasi Visible Light Communication Sebagai media transmisi Radio Streaming. Bandung: Telkom University.

[5] Darlis A., Lidyawaty,L.,Jambola, L., \& Wulandari, N. (2014). Implementasi Sistem Komunikasi Video menggunakan Visible Light Communication (VLC). Jurnal Reka elkomika. 2 (3): 160-173.

[6] Kurniawan (2009). http://journal.amikom.ac.id/index.php /KIDA/article/viewFile/4656/2354.

[7] Yohanos Wigig Sjono (2012). https://www.scribd.com/doc/217731 669/Jurnal-Elektronika-Daya-YohanesWigig-Sarjono.

[8] Hanafi (2013). http://jurnal.pnl.ac.id/wpcontent/plugins/Flutter/files_flutter/1 367391338JurnalHanafi2013.pdf. 